\title{
Akarsuların Önemi ve Farklı Kullanımları Üzerine Bir Değerlendirme
}

\author{
An Evaluation on Importance and Different Use of Rivers
}

\author{
Nurhan KOÇAN*1,a, Nüket ANKARALI ${ }^{1, b}$ \\ ${ }^{1}$ Bartın Üniversitesi Mühendislik Mimarlık ve Tasarım Fakültesi Peyzaj Mimarlı̆̆ı Bölümü
}

• Geliş tarihi / Received: 14.02.2020 ～• Düzeltilerek geliş tarihi / Received in revised form: 08.08.2020 • Kabul tarihi / Accepted: 12.08.2020

\section{$\ddot{O} z$}

Doğal kaynaklar insanların yerleşim alanı seçiminde önemli faktörler olmuştur. Bu nedenle ilk yerleşmelerin çoğu su kenarlarında kurulmuştur. Su kaynaklarının insan üzerindeki fiziksel ve psikolojik yönden olumlu etkileri her zaman insanları suya çekmiştir. Bu çalışmada Avrupa ve ülkemiz örneğinde akarsuların farklı kullanımlarının belirlenmesine yönelik araştırmalar yapılmıştır. Bu kapsamda yurt dışı kentlerden Sırbistan'ın Belgrad ve Novi Sad kentlerinden geçen Sava ve Tuna Nehirleri (2014 ve 2016), Çekya'nın Prag kentinden geçen Vltava Nehri ve Karlovy Vary kentinden geçen Hluboka Nehri (2014 ve 2016), Macaristan'ın Budapeşte kentinden geçen Tuna Nehri (2014 ve 2017), Ukrayna'nın Kiev kentinden geçen Dinyeper Nehri (2018) ve yakın çevrelerinde incelemeler yapılmıştır. Yurt içi kentlerinden ise Nevşehir'in Avanos ilçesinden geçen Kızılırmak Nehri (2016), Edirne'den geçen Meriç Nehri (2017) ile Eskişehir'den geçen Porsuk Çayı (2018) ve yakın çevrelerinde sörvey çalışmaları yapılmıştır. Çalışmada örnek olarak seçilen akarsular ve yakın çevrelerinde en çok tercih edilen kullanımlar belirlenmiştir. Bu tespitin akarsu kenarlarında yapılacak peyzaj düzenlemelerinde alana getirilebilecek kullanım türünün belirlenmesinde rehberlik edeceği düşünülmektedir.

Anahtar kelimeler: Akarsu, Akarsu Peyzajı, Peyzaj Tasarımı, Rekreasyon

\begin{abstract}
Natural resources have been important factors in the selection of residential areas. For this reason, most of the first settlements were built on the water's edge. Physical and psychological positive effects of water resources on people have always drew people into water. In this study, different uses of rivers in the example of the world and our country were carried out to determine usage preference. In this context studies were done that is Sava and Danube Rivers passing through Belgrade and Novi Sad cities of Serbia (evaluated in 2014 and 2016), Vltava River passing through Prague and Hluboka River passing through Karlovy Vary (evaluated in 2014 and 2016) cities of Czech Republic, Danube River passing through Budapest city of Hungary (evaluated in 2014 and 2017) and Dnieper River passing through Kiev city of Ukraine (evaluated in 2018). Surveys have been carried out in the Klzllirmak River passing through Avanos district of Nevşehir (evaluated in 2016), Meriç River passing through Edirne (evaluated in 2017), Porsuk Stream passing through Eskişehir (evaluated in 2018) and its vicinity. In the study, the most preferred uses in the selected streams and their close surroundings were determined. It is thought that this study will guide the determination of the type of use that can be brought to the area in the landscape arrangements to be made at the river borders.
\end{abstract}

Keywords: River, River Landscape, Landscape Design, Recreation

\footnotetext{
*a Nurhan Koçan, nkocan@bartin.edu.tr, Tel: (0378) 22351 58 , orcid.org/0000-0001-9433-7007

${ }^{\mathrm{b}}$ orcid.org/0000-0001-9433-7007
} 


\section{Giriş}

Akarsular ekolojik ve ekonomik anlamda değerli doğal kaynaklardır. Bu nedenle yüzlerce y1ldır çeşitli amaçlarla kullanılmışlardır. Bu kaynaktan ekolojik değerlerine zarar vermeden yararlanmak öncelikli amaçtır. Bu nedenle bu alanların doğru şekilde planlanıp tasarlanması ve kamu yararı gözetilerek planlanması gerekir (Önen, 2006). Özellikle son yıllarda kent yaşamında doğadan kopan kentliler için akarsu gibi bir kaynağın varlığı kentliler için yeni ekonomik ve ticari olanakları beraberinde getirmiştir. Bazı durumlarda ihmal edilen ve kirletilen kentsel doğal su elemanlarının kent için öneminin ve suyun mekan tasarımlarına kattığı gücün değerinin anlaşılmasıyla günümüzde farkındalığı artmıştır (Cendere, 1998).

\subsection{Akarsuların Önemi ve Akarsu Kıyı Kullanımlart}

İnsan temel gereksinimleri nedeniyle su ile bağlıdır. İnsanlar yaşam alanlarını ya su kenarlarında kurmakta ya da kanallar ile yaşadıkları yere suyu taşıyarak hayatlarını sürdürmektedirler (Haris ve Dines, 1988). Suyun insan üzerinde yarattığ estetik etki, kent içindeki doğal su kaynaklarına önem verilmesinde etkilidir (Anonim, 1998).

Kentleşmenin hızıyla ortaya çıkan doğal alan ve kaynaklardaki bozulmalardan dolayı doğal kaynakların korunması ve geliştirilmesi önem kazanmıştır. Kent içindeki su varlığı, kentlerin gelişimine etki eden önemli bir faktördür. $\mathrm{Bu}$ nedenle bu alanların kamu yararı gözetilerek doğru şekilde planlanıp tasarlanması gerekir. Su kaynaklarının insan üzerinde fiziksel ve psikolojik yönden olumlu etkileri vardır. Çevre üzerinde ise estetik ve fonksiyonel yönden olumlu özellik kazandırırlar (Önen, 2006). Suyun manzara oluşturması ve insanları dinlendirme etkisi önemli bir güçtür. Akarsular mekana canlılık ve heyecan katarak insanları çeken ve etkileyen görüntüler oluşturmaktadır (Aksulu, 2001) (Şekil 1a, Şekil $1 b)$.
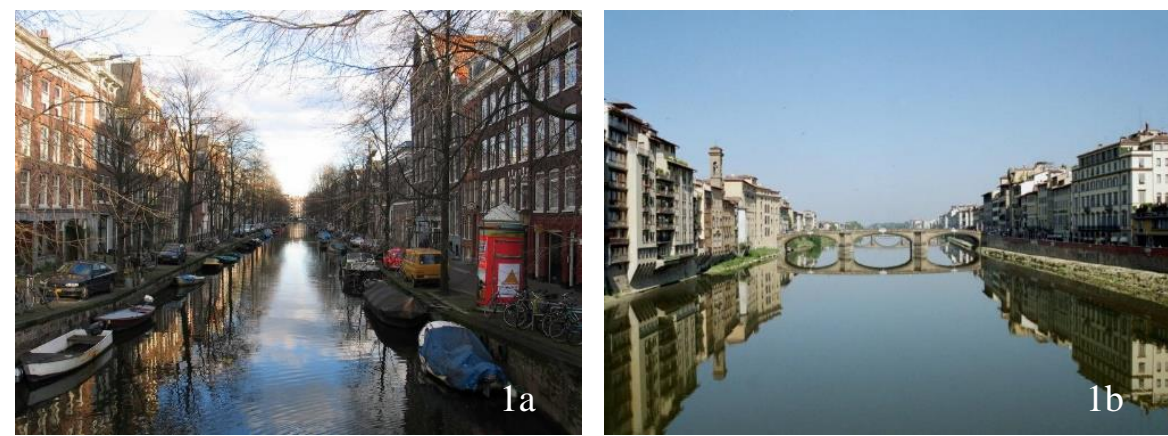

Şekil 1. (a) Amsterdam Kanalları, Hollanda (URL-9, 2019), (b) Arno Nehri, Floransa, İtalya

Suyun estetik, yansitma ve derinlik yaratma etkileri vardır. Bunlar mekanı zenginleștirerek insanlar için kaliteli mekanlar olușturur (Anonim, 1998a). Kapalı ve kuşatılmış bir kentsel mekanda bir su kaynağının insana fiziksel ve ruhsal olumlu etki yaptığı bilinen bir gerçektir. Planlama çalışmalarında suyun bu etkilerine ek olarak yapılacak bitkisel ve yapısal tasarımlarla mekanın özellikleri zenginleştirilebilir (Hattapoğlu, 2004).

Akarsu kıyı kullanımları; ulaşım, endüstri, ticari, yerleşim, kültür ve eğitim ile rekreasyon amaçlı kıyı kullanımları şeklinde sıralanabilir.

\subsubsection{Ulaşım Amaçlı Kullanımlar}

Kiyılarda, yolcu ve ticaret limanları, yat tesisleri, iskeleler, sudaki ulaşımı destekleyen demirleme alanları ve küçük esnafa ait işletmeler yer almaktadır. Ulaşım amaçlı kullanımlar seyahat amaçlı ulaşım, ticaret amaçlı ulaşım, rekreasyon amaçlı ulaşım olmak üzere üç farklı şekilde değerlendirilmektedir. Kıyı kentlerinde kıyıda bulunan endüstri tesislerinin taşınması veya faaliyetini durdurmas1 sonucu bu alanlarda rekreasyon ve yenileme amaçlı projeler uygulamaya konulmuştur. Shadwell Basin (Doğu İngiltere) de bu tür bir alandır (Şekil 2).

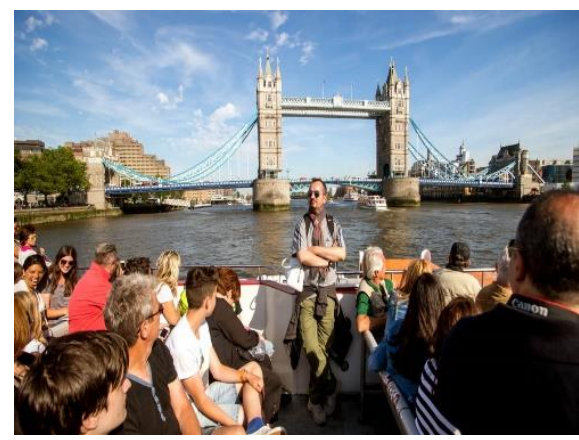

Şekil 2. Shadwell Basin (URL-11, 2019) 
Alan, endüstrinin çekilmesiyle restoran, yat, kano, yelkencilik kulüpleri ile bir rekreasyon alanına dönüştürülmüştür (Kobayashi, 1990). Seyahat amaçlı ulaşım için kıyılarda iskeleler, yolcu ve yat limanları bulunur (Musayev, 2003). Kıyı alanlarında rekreasyon amaçlı ulaşım bisiklet, paten yolları, yürüyüş yolları, vb. yollar ile sağlanmaktadır. Rekreasyonel amaçlı kıyı ulaşım alanları kent ve kentliye yarar fiziksel ve ruhsal birçok fayda sağlayan kullanımlardır.

\subsubsection{Endüstri Amaçlı Kullanımlar}

Kıyıların endüstri amaçlı tercih edilmesinin temel nedenleri; (Karabey, 1978).

- Kıyının kara ve su ulaşımı arasında geçişi sağlayan bir kırılma noktası olması ve depolama kolaylığı,

- Endüstrinin ürettiği atıkların arıtılmadan su aracılığıyla uzaklaştırılabilmesi ve bunun maliyetinin olmamas1,

- Kıyının hammadde kaynağı (kum, çakı1, kalker, deniz bitkileri) olarak kullanılabilmesi,

- Akarsu ve denizlerin ticari açıdan ulaşım aracı olarak kullanılmasıdır (Tekeli, 1976).

Kıyılarda deniz ve akarsu taşımacılı̆̆ındaki gelişmeler endüstri devrimi ile artış göstermiştir. $\mathrm{Bu}$ gelişim liman sayısının artmasına neden olmuştur. Kara taşımacılığına göre suyoluyla taşımacılık maliyetinin düşük olması liman yapımını teşvik etmiştir. Böylelikle kıyılardaki endüstri kullanımı artmıştır (Özmert, 1997) (Şekil 3).

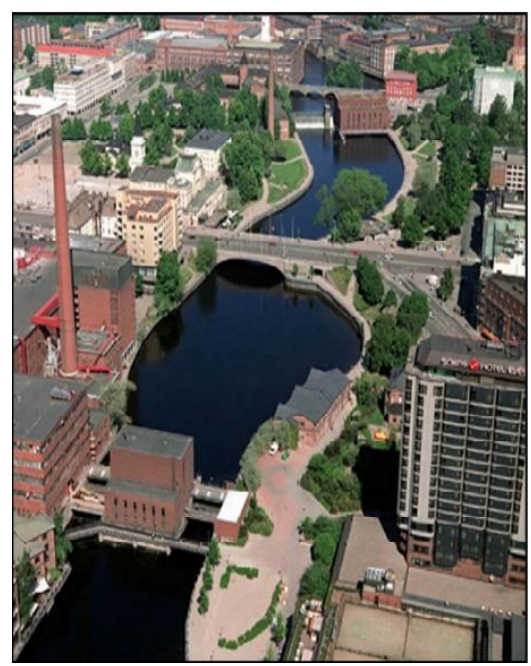

Şekil 3. Sanayii yapıları, Tampere, Finlandiya (Hattapoğlu, 2004)

\subsubsection{Ticari Amaçlı Kullanımlar}

Ticari amaçlı kullanımlar halka rekreasyonel mekanlar sunmanın yanı sira para kazanmayı hedefleyen kullanımlardır. Oteller, restaurantlar, kafeler, alışveriş mekanları bu kullanımlara örnek verilebilir. Birçok rekreatif aktiviteye imkan tanıyan kıyılar kent ve kentli için suya yakın olmak ve sudan faydalanmak adına bulunmaz mekanlardır. Ticari amaçlı kullanımlara örnek olarak; Avustralya Yara Nehri rekreasyon imkanı sunan güzel bir uygulamadır (Breen ve Rigby, 1996) (Şekil 4).

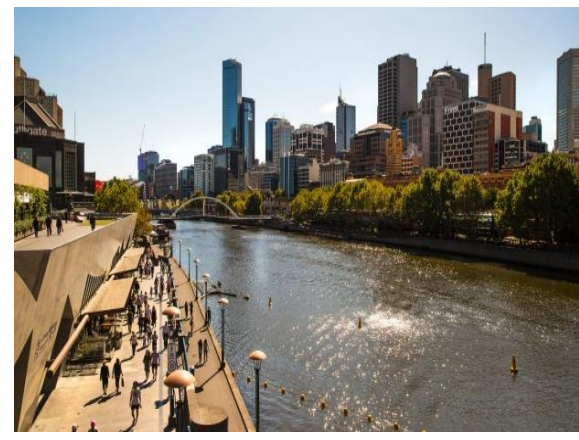

Şekil 4. Yarra Nehri, Melbourne, Avustralya (URL-12, 2019)

\subsubsection{Yerleșme Amaçlı Kullanımlar}

Tarih boyu kıyılar doğal ve çevresel özellikleri bakımından yerleşim için tercih edilen öncelikli yerler olmuştur. İnsanlar akarsuların oluşturduğu tüm riskler ve tehlikelere rağmen akarsu kenarlarını kullanmaya devam etmektedir (Breen ve Rigby, 1996).

Kentlerin kuruluşunda nehirler kentlerin iskeletini oluşturmuş caddelerin, sokakların, parkların ve diğer kent mekanların şekillenmesinde etken olmuşlardır (Hattapoğlu, 2004). Su ile buluşan kentlerin kendine özgü bir karakteri vardır (Koskof, 1992) (Şekil 5).

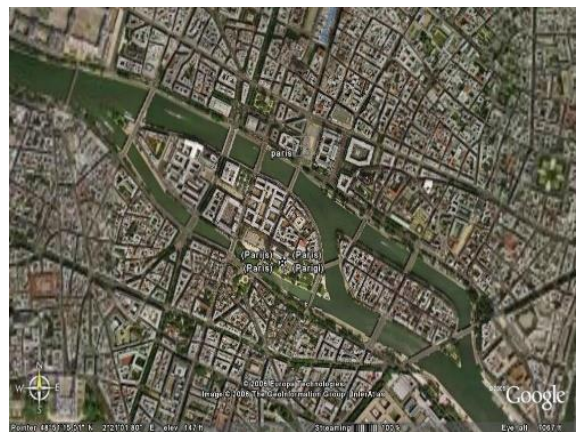

Şekil 5. Sein Nehri'nde su üzerinden geçişler, Paris (URL-1, 2018) 


\subsubsection{Kültürr ve Eğitim Amaçlı Kullanımlar}

Kültür ve eğitim amaçlı kıyı kullanımlarına festival ve konser alanları, müzeler, parklar, çocuk oyun alanları, spor alanları, sergi alanları gibi kültürel ve eğitimsel amaçlı kullanımlar örnek olarak verilebilir. $\mathrm{Bu}$ tür kültürel etkinlikler kıyıları cazip hale getirirken insanları gezerken
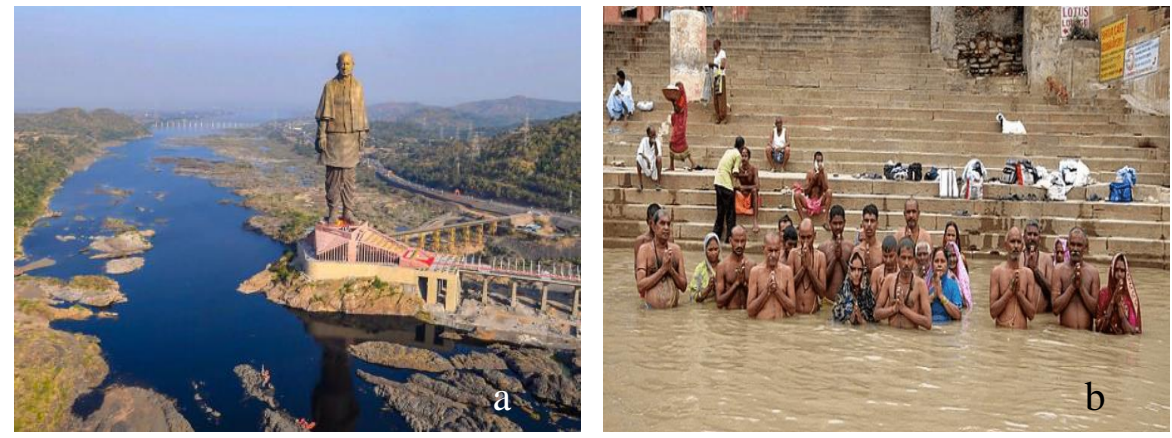

Şekil 6. (a) Sardar Vallabhbhai Patel heykeli, Narvada, Kevadiya, Hindistan (URL-13, 2019), (b) Haç ibadeti, Ganj Nehri, Hindistan (URL-10, 2019)

\subsubsection{Rekreasyonel Amaçlı Kullanımlar}

Rekreasyonel amaçlı kullanımlar kıyılarda en çok tercih edilen kullanım türünü oluşturmaktadır. Kıyılar açık yeşil alan potansiyelinin yoğun olduğu kentlilerin nefes aldığ 1 noktalarıdır öğrenmeye de teşvik etmiştir. Su bazı toplumlarda ya da dinlerde kutsal sayılır. Hindular Ganj Nehri sularının insanı günahlarından arındırdığına inanırlar. Binlerce insan her yıl hacı olmak için bu nehre girer. İnsanlarda arınma duygusu psikolojik açıdan rahatlama yaratır (Hattapoğlu, 2004) (Şekil 6a, Şekil 6b).

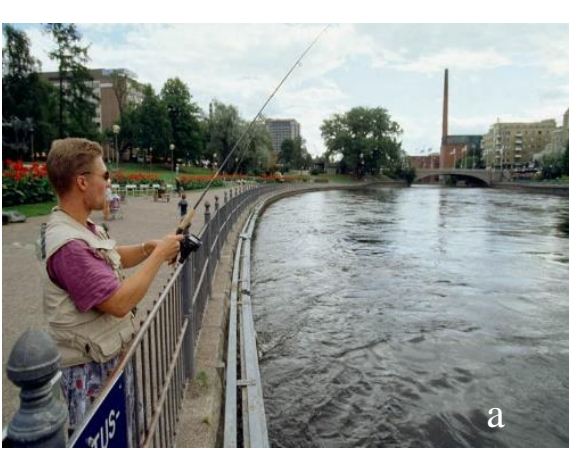

(Anonim, 1998). Su yüzeyinde ve içinde, su kıyısında pek çok rekreasyon aktiviteleri düzenlenebilir. Örneğin; yüzme, dalma sporu, kano yarışları, avlanma, tekne gezileri, yürüyüş, piknik alanları bunlardan bazılarıdır (Erdal, 2003) (Şekil 7a, Şekil 7b).

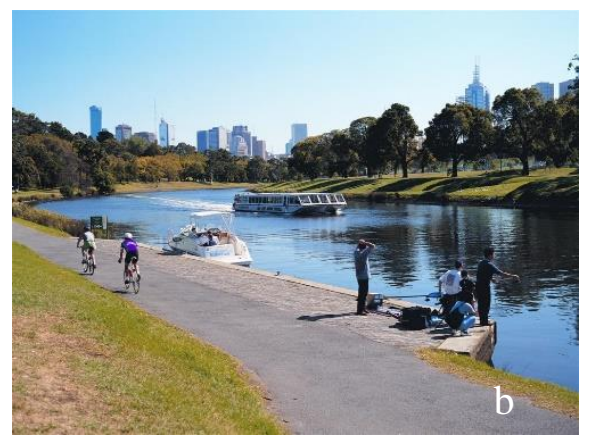

Şekil 7. (a) Tampere kıyısında rekreasyon (Hattapoğlu, 2004), (b) Rekreasyonel kullanımlar, Yarra Nehri, Melbourne, Avustralya (URL-12, 2019)

\section{Materyal ve Yöntem}

Çalışmada örnek olarak seçilen kentlere farklı mevsimlerde gidilerek sörvey çalışması yapılmıştır. Böylece farklı mevsim ve ay olmak üzere günün farklı zaman dilimlerinde alanın kullanıc1lar yönünden nasıl tercih edildiği, alan bütünü dahilinde hangi aktivitelerin yapıldığının tespiti yapılmıştır. Yurt içi kentlerden örnek alanların incelenmesi ve program elemanlarının tespiti için Türkiye'de en aktif olarak kullanılan ve bilinen nehirler seçilmiştir. Nevşehir Avanos Kızılırmak Nehri (2016), Edirne Meriç Nehri (2017) ile Eskişehir Porsuk Çayı (2018) ve yakın çevrelerinde sörvey çalışmaları yapılmıştır. Yurt dış1 kentlerden örnek alanların incelenmesi ve program elemanlarının tespiti için Surbistan Belgrad ve Novi Sad, Sava ve Tuna Nehirleri (2014 ve 2016), Çekya Prag Vltava Nehri ve Karlovy Vary Hluboka Nehri (2014 ve 2016), Macaristan Budapeşte Tuna Nehri (2014 ve 2017), Ukrayna Kiev Dinyeper Nehri (2018) ve yakın çevrelerinde sörvey çalışmaları yapılmıştır. Yapılan gözlem ve değerlendirmelerle elde edilen tespit sonuçları fotoğraflarla kayıt altına alınmıştır. Diğer yandan alanın doğal ve kültürel verilerine yönelik literatür taraması yapılmıştır. Çalışmanın sonucunda Avrupa'da ve Türkiye'de 
nehir kenarları ve yakın çevrelerinde en fazla tercih edilen ve uygulamada en fazla görülen kullanım türleri ortaya çıarılmıştır. Bu tespitin akarsu kenarlarında yapılacak peyzaj düzenlemelerinde kullanım türünün belirlenmesinde rehberlik edeceği düşünülmektedir.

\section{Bulgular}

\subsection{Avrupadan Akarsu Kıyısı Düzenleme Örnekleri}

Avrupa örneklerinden 4 ülkeye ait nehir örnekleri yerinde görülerek incelenmiştir.

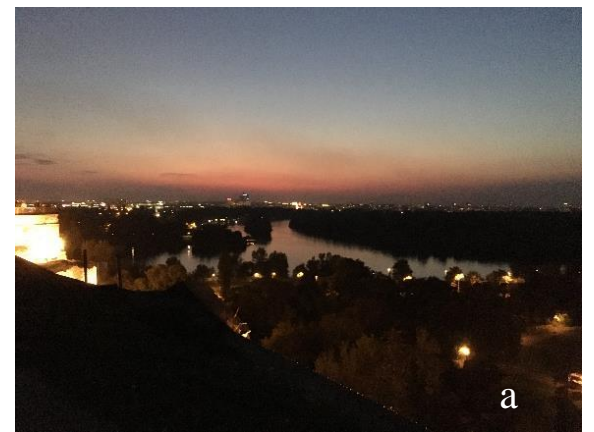

Şekil 8. (a) Sava ve Tuna Nehirleri birleșim noktası, Belgrad, (b) Tuna Nehri üzerindeki farklı köprülerden bir görünüm

Sava ve Tuna Nehirleri’nin kesiştiği bölgede irili ufaklı birkaç ada oluşmuştur. Bu adalardan en önemlisi Ciganlija Adası'dır. Doğal yaşamın

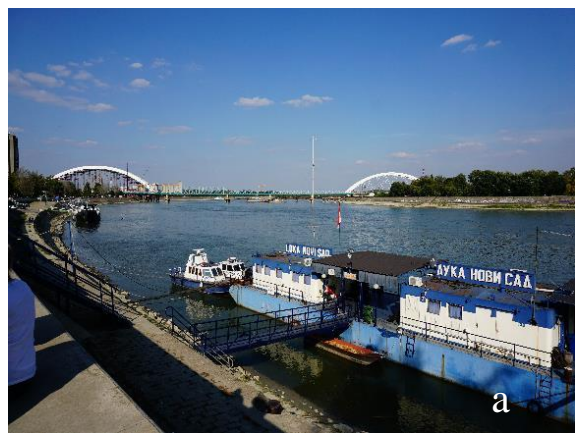

Şekil 9. (a) Tuna Nehri üzerinde tekne turları, Novi Sad, (b) Tuna Nehri kenarı dinlenme alanları, Novi Sad

Bölgede akarsu kıyllarında yeni bir turistik ve kültürel mekan oluşmuştur. Nehir kıyısı boyunca restoran ve ticaret yapıları yer almaktadır. Nehir kıyısının düzenlenmesi ile yukarıdan nehirlerin birleşme yerini izleme, oturma, dinlenme, yemeiçme, bisiklete binme, alışveriş vb, etkinlikleri içeren aktivite olanaklarıyla bölgeyi çok sayıda kişi ziyaret etmektedir. Nehir kenarları boyunca düzenlenen yeşil alanlar, dinlenme ve eğlenme
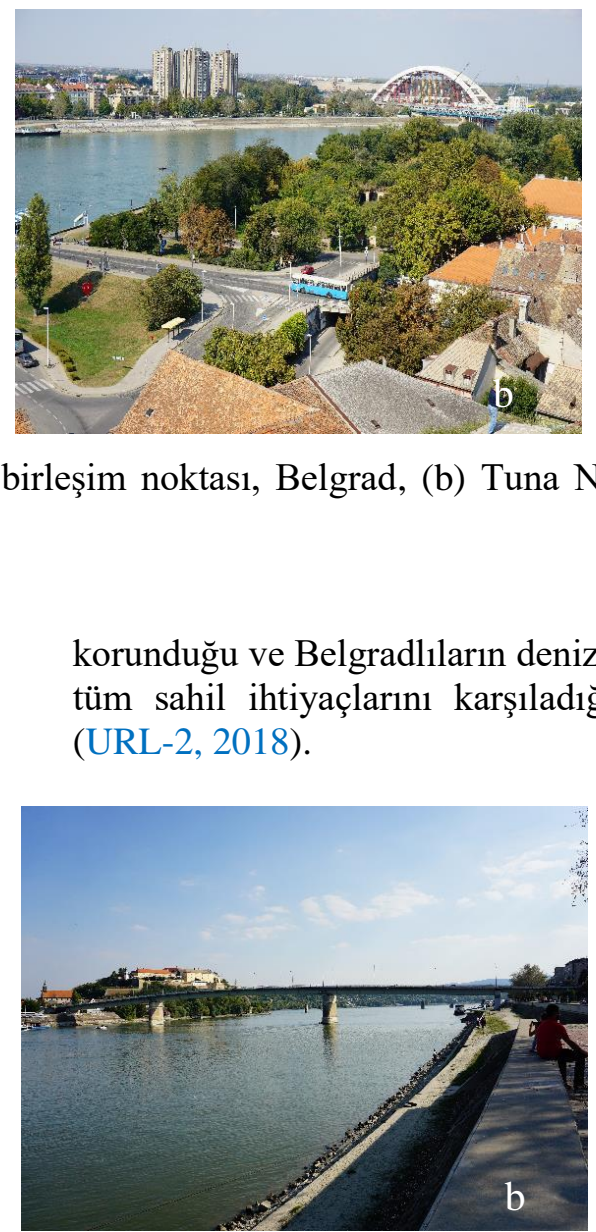

\subsubsection{Sirbistan (Belgrad, Novi Sad) Sava ve Tuna Nehirleri}

Belgrad'ta kentin Kalemegdan ismi verilen kesiminde sol yönden akıp gelen Sava Nehri Tuna Nehri ile birleşmektedir. Buradan itibaren iki nehrin suları birbirine karışmakta ve Sava Nehri son bulmaktadır. Tuna Nehri ise çoğalarak Karadeniz'e dökülünceye kadar devam etmektedir. Tuna Nehri, Avrupa'nın en uzun ikinci nehridir. Yaklaşık 2800 kilometre uzunluğunda olan nehir on ülkeden geçerek Karadeniz’e dökülür (URL-2, 2018) (Şekil 8a, Şekil 8b).

korunduğu ve Belgradlıların denizi olmadığı halde tüm sahil ihtiyaçlarını karşıladığı ada burasıdır (URL-2, 2018).

alanlarıyla çeşitlendirilmiştir. Alan iki kotta çözümlenmiştir. Kotlar arasında çeşitli yüksekliklerde duvarlar vardır. Üst kotta araç yolu ve yürüyüş yolu bulunmakta, su ile bire bir ilişkide olan alt kotta ise gezinti yolları yer almaktadır. Alan içindeki döşeme elemanları doğal taş ve granit malzemedir (Şekil 9a, Şekil 9b). 


\subsection{2 Çekya Vltava (Prag) ve Hluboka (Karlovy Vary) Nehirleri}

Tarihi yapılarıyla önemli bir şehir olan Prag'1 özgün kılan nehir olan Vltava Nehri 435 km boyunca Çek Cumhuriyeti topraklarına eşlik etmektedir. Azgin su anlamına gelen Vltava günümüzde dalga setlerle ve açılan su kanallarıyla 1slah edilmiştir. Nehrin şiddetli akan suları, üzerine inşa edilen köprülere defalarca zarar vermiştir. Bu yüzden nehir ve çevresi şehrin fakir halkın yerleşim yeri olmuştur. Nehir çevresinde tekne turları yapabilmektedir. Sandal ve su bisikleti kiralanabilecek noktalar bulunmaktadır (URL-3, 2019) (Şekil 10a, Şekil 10b).

Alanda yürüyüş yolları, kafeler, ticari alanlar, hediyelik eşya satış birimleri, yeme içme noktaları, kültür- sanat ve eğlence alanlarını

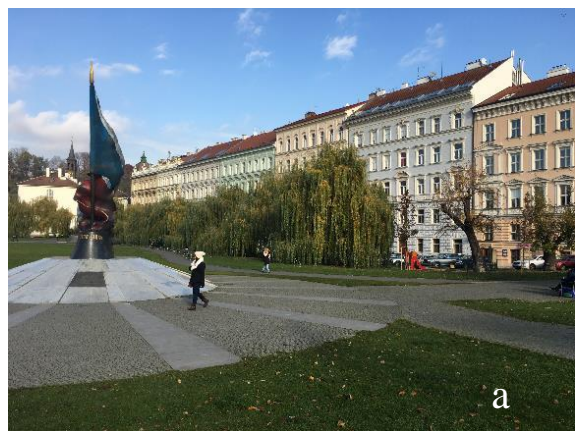

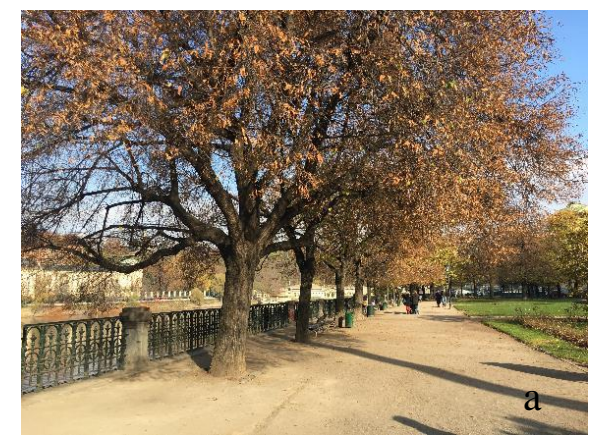

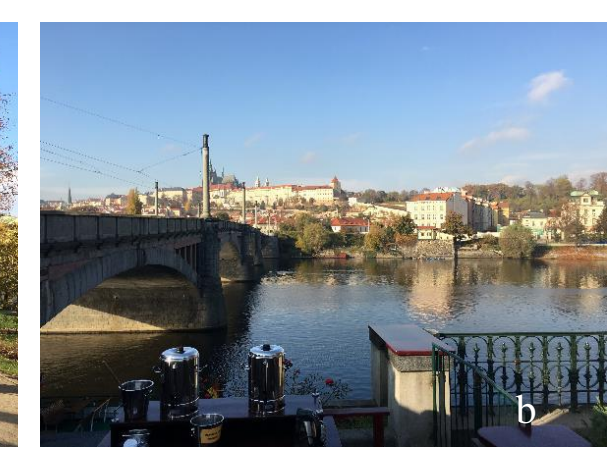

Şekil 10. (a) Tuna Nehri kenarı yürüyüş yolları, Prag, (b) Tuna Nehri üzerinde yer alan köprülerden biri ve dinlenme alanları, Prag

Heykellerle süslü köprülerde el sanatları, sokak sanatçıları, resim, heykel, müzik gibi aktiviteler yanında şehri fotoğraflamak ve görmek isteyenler yoğun olarak kente gelmektedir. Dış cephelerde ve yaya yollarında bazalt ve doğal taşlar kullanılmıştır. Kıyıdaki donatılar kıyı görünümünü zenginleştiren ögelerdir. Nehir kanalı boyunca bronz ve taş heykeller alana estetik katmaktadır. Yeni düzenleme kapsamında geniş yaya yolu yer almaktadır. Nehre kimlik katan tarihi ve sanatsal özellikler köprülerle nehir boyunca alan hareketlendirilmiştir. Bitkiler ve aydınlatma elemanları ile alan gece de çok sayıda kişiyi kıyıya çekmektedir. Nehir kenarı düzenlemeler kentin ticari, mekansal ve rekreasyonel değerini arttırmıştır (Şekil 11a, Şekil 11b).

içermektedir. Nehirde tekne ve botlarla gezme, balık tutma ve su sporları yapma imkanı sağlanmıştır (Şekil 12a, Şekil 12b).

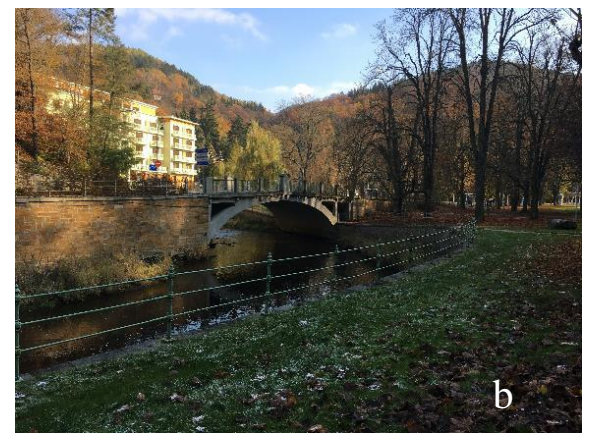

Şekil 11. (a) Nehir kenarına yakın konumlanmış, resmi binalar, meydan ve park, Prag, (b) Hluboka Nehri ve çevresi, Karlovy Vary 

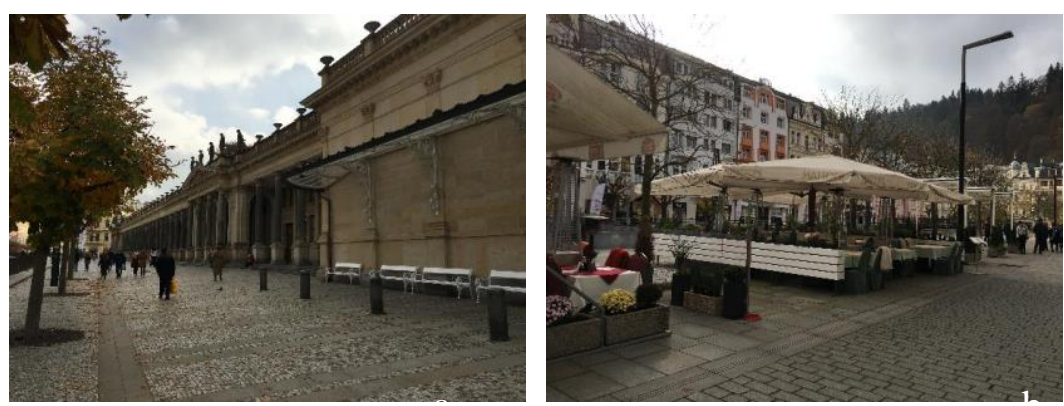

Şekil 12. (a) Nehir çevresinde yer alan kültür ve sanat yapıları, Karlovy Vary, (b) Nehir çevresinde yer alan kafeterya ve restoranlar, Karlovy Vary

\subsubsection{Macaristan (Budapeşte) Tuna Nehri}

Tuna Nehri'nin iki yakasındaki Buda ve Peşte şehirlerinin 1873 yılında birleşimiyle oluşan Budapeşte, Orta Avrupa'yı ziyarete çıkan turistlerin uğramadan geçmediği bir şehirdir. Tuna Nehri'nin etrafında özenle kurulmuş ve bu nehrin kattığı güzellikle hayat bulan kent, ziyaretçilerine hem tarihe yolculuk yaptırmakta hem de güncel turizm isteklerini yaşatmaktadır. Tuna Nehri'nin iki yakasını birleştiren köprülerin özellikle gece görünümleri ziyaretçileri etkilemektedir. 120 rrmaktan beslenerek 10 ayrı ülke topraklarından geçen Tuna Nehri'nin en güzel göründüğü kent olarak gösterilen Budapeşte, adeta açık hava müzesi gibidir. İki yakayı birleştiren birçok köprü ile Tuna Nehri'nin etrafindaki tarihi binalar, Gellert Tepesi'nden büyüleyici bir görüntü sunmaktadır
(URL-4, 2019). Nehir kıyısında yer alan yapılar, otel, park alanları, kilise ve yönetim binaları gibi çoğunluğu tarihi olan yapılardır. Konut alanları ise kıyının gerisine taşınmıştır.

Nehir ile kara arasında farklı iki kot bulunmaktadır. Üst kotta oturma elemanları, yürüme yolları ve seyir terasları bulunurken alt kotta, feribot ve gezinti botları için iskeleler yer almaktadır. Nehrin her iki yanında kentin eski yerleşimine ait önemli ve büyük tarihi yapılar yer almaktadır. Nehir kenarında otoyol vardır ancak halk yüzünü nehre dönerek kentin bu yoğun atmosferinden kurtulmaktadır. Kıyının bazı bölümlerinde yaya yolu genişlemekte ve az bir eğimle suya doğru inmektedir. Alanda gece aydınlatmaları yapılmış olup aydınlatmalar alana çekicilik katmaktadır (Şekil 13a-16b).
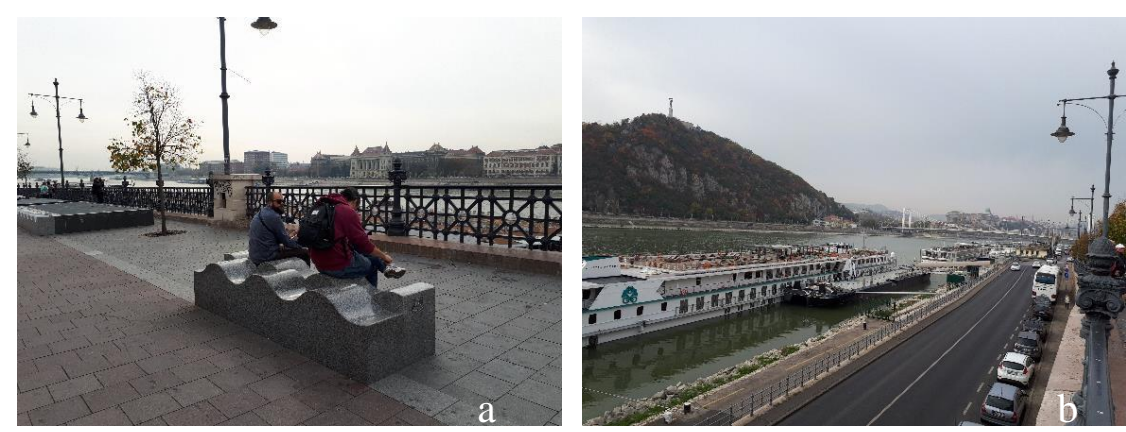

Şekil 13. (a) Nehir çevresinde yer alan oturma birimleri, Budapeşte, (b) Farklı kotlarda yer alan kent kesiti, Budapeşte
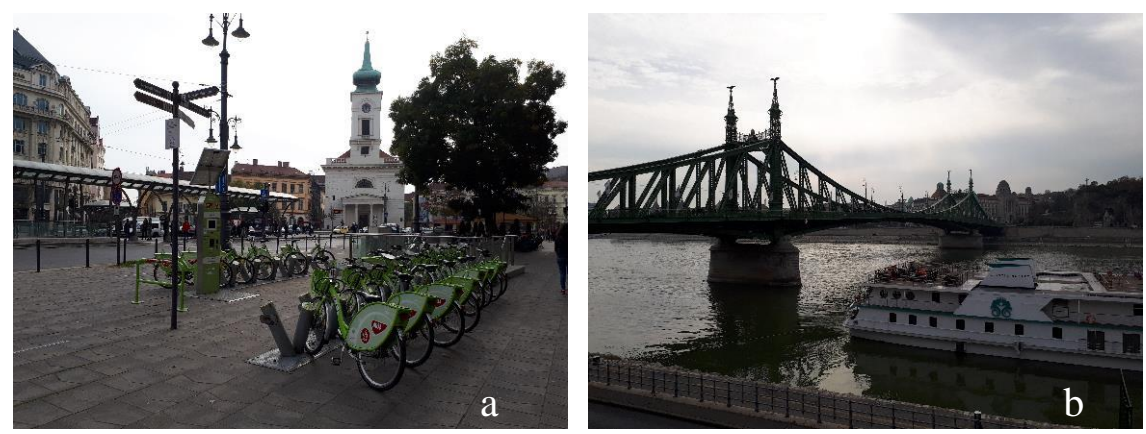

Şekil 14. (a) Nehir çevresinde yer alan bisiklet kiralama ve park noktaları, Budapeşte, (b) Yeşil Köprü (Liberty Bridge) ve tekne turları, Budapeşte 

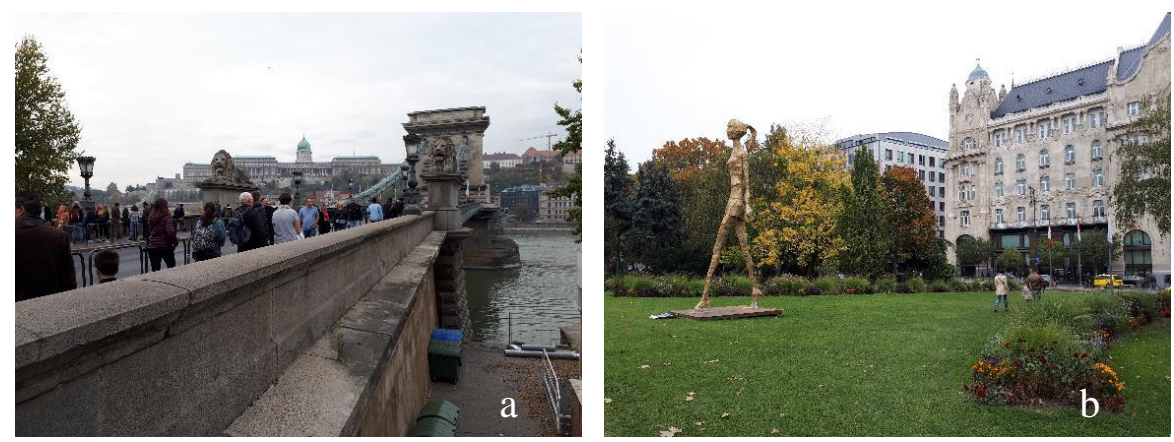

Şekil 15. (a) Chain Köprüsü ve kenti gezenler, Budapeşte, (b) Nehir kenarında yer alan parklardan bir görünüm, Budapeşte
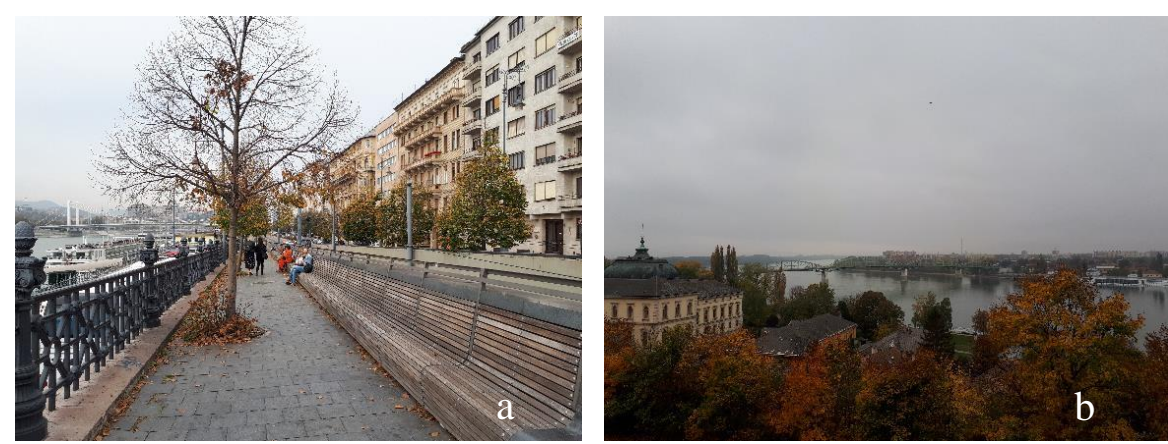

Şekil 16. (a) Nehir kenarında farklı kotlarda çözülmüş oturma ve seyir alanları, Budapeşte, (b) Nehir ve kentin sonbahar görüntüsü, Budapeşte

\subsubsection{Ukrayna (Kiev) Dinyeper Nehri}

Dinyeper (Dnipro) Rusya ile Ukrayna topraklarının geçen görünüm açısından zengin bir nehirdir. İdil ve Tuna nehirlerinden sonra Avrupa'nın üçüncü uzun nehridir. $2290 \mathrm{~km}$ mesafe uzunluğundaki bu nehir, Valday Dağları yaylasının güneyinden doğar ve Smolensk'e ulaşır, Türkçe adı Beyaz Rusya olan Belarusa doğru uzanır, Beyaz Rusya'nın doğu kısmından geçerek Ukrayna'ya ulaşır. Sol tarafindan Desna Irmağı ile birleşen bu nehir daha sonra Kiev'e geçer. Dinyeper Yaylası'nı bir eğimle dolaşır ve kıyı kısmını kısmen kapattığı bir haliç meydana getirerek Odessa'nın doğusundan devam ederek Karadeniz'e dökülür (URL-5, 2019).

Dinyeper Nehri kenarında yerli halk ve yabancı turistlerin turizm ve rekreasyon amaciyla

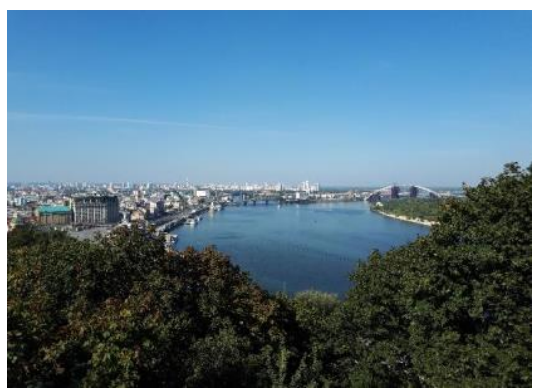

bulabildiği birçok aktivite alanı vardır. Oturma ve dinlenme alanları, kafeterya ve restoranlar, balık tutma, tekne gezintisi, lunapark, meydan aktiviteleri, bisiklet gezintisi, fotoğraf çekme gibi aktiviteler için nehir kenarında çok sayıda tesis ve alan ayrılmıştır. Dinyeper Nehri kenarında gezinti alanları, oturma birimleri, lunapark ve restore edilen tarihi binalar ve geniş bir meydan yer almaktadır. Bu meydan, insanların toplandığ 1 ve birçok aktivitenin gerçekleştirildiği alandır. Nehir boyunca devam eden yaya yolunda döşeme farklarıyla monotonluk kırılmıştır. Bu şekilde farklı aktiviteler için mekanların tanımlanması ve ayrılması da sağlanmıştır. Kıyı düzenleme projesi kapsamında, nehir kıyısı, tur botları ile gezilebilmektedir. Nehir kıyısındaki turistik ve ticari yapılar kent için önemli bir yer tutmaktadır (Şekil 17a-18b).

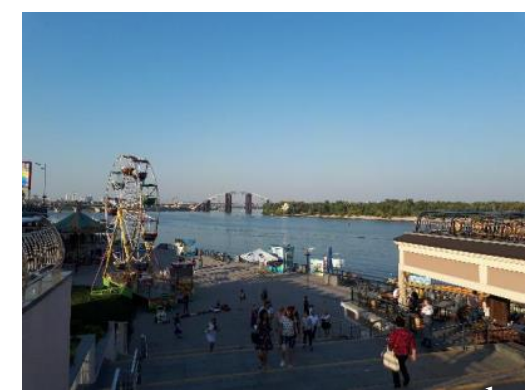

Şekil 17. (a) Dinyeper Nehri, Kiev, (b) Nehir kenarındaki eğlenme ve dinlenme alanları, Kiev 

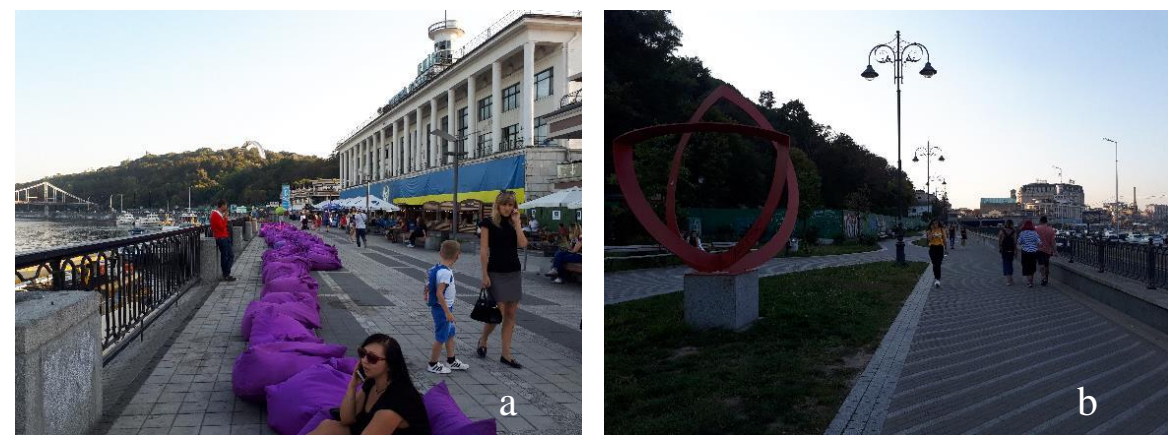

Şekil 18. (a) Nehir kenarında yayalaştırılmış mekanlar, Kiev, (b) Dinyeper Nehri kenarında yürüyüş yollarına eşlik eden sanatsal objeler, Kiev

\subsection{Türkiye'den Rekreasyonel Kullanımı Olan Akarsu Kıyısı Düzenleme Örnekleri}

Türkiye'den üç örnek yerinde görülerek incelenmiştir.

\subsubsection{Kızılırmak Avanos-Nevşehir}

Nevșehir'in en büyük akarsuyu Kızılırmak'tır. Bu ırmak Avanos ilçesinden Nevşehir İli’ne girip il
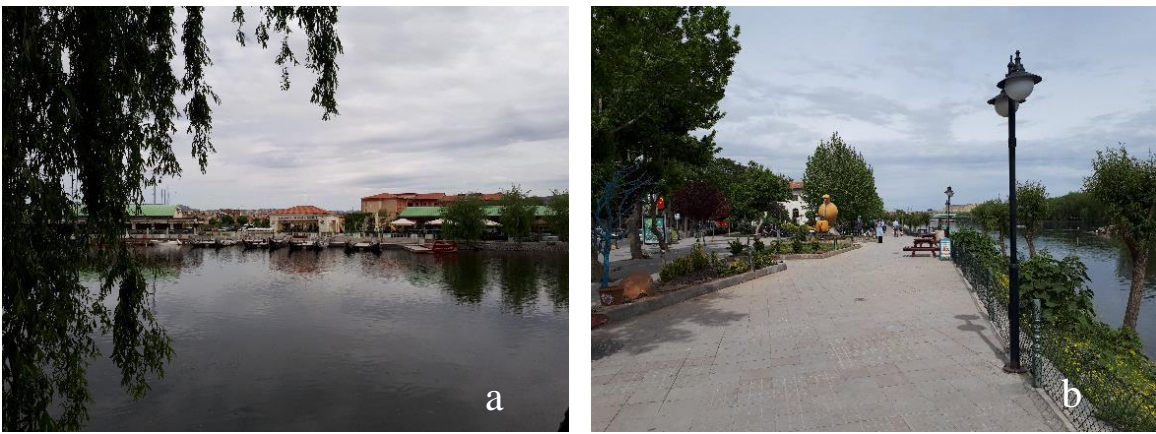

Şekil 19. (a) Nehir üzerinde gezinti yapan tekne ve bot kiralama alanları, Avanos, (b) Nehir kenarı yürüyüş yolları ve dinlenme alanları, Avanos

\subsubsection{Edirne Meriç Nehri}

Meriç Nehri, Balkanlar'ın en büyük nehirlerinden biridir. Nehir Bulgaristan'dan doğar. Buradan Edirne'den geçip Ege Denizi'ne ulaşır. Toplamda 490 kilometre uzunluğunda olup; Arda, Ergene ve Tunca başlica beslendiği akarsu yataklarıdır. Manzarası ile çoğunluğu yerli olmak üzere çok sayıda turist çekmektedir. Nehir kenarında oturma ve dinlenme alanları, yürüyüsş yolları, çocuk oyun alanı, kamp alanı gibi rekreasyon etkinliklerine uygun düzenlenmiş alanlar bulunmaktadır. Nehir üzerindeki köprü topraklarını ikiye böler. Arapsun (Gülşehir)'den sonra il sinırlarını terkeder (URL-6, 2019). Avanos Nehri boyunca oturma ve dinlenme alanları, kafeterya ve restoranlar, park alan1, bisiklet ve yürüyüş yolları, seyir terasları, nehir botu ve kay1kla gezinti yapılabilecek alanlar bulunmaktadır. Yine alan çevresinde kente özgü el sanatları ve hediyelik eşyaların alınabileceği dükkanlar yer almaktadır (Şekil 19a, Şekil 19b). uzunluğu ve görünümü ile dikkat çekmektedir (URL-7, 2019).

Meriç Nehri kenarında dere 1slah çalıșmaları devam etmektedir. Derenin daralan kesimlerinde genişleme, duvar yapımı gibi çalışmalarla suyun kente verdiği zarar önlenmeye çalışılmaktadır. Nehrin her iki yanındaki stabilize yol bazı kesimlerde asfalt bazı kesimlerde ise sıkıştırılmış mıcır şeklindedir. Yol kenarında toz hakim olup yaya yürüyüşünün kalitesini olumsuz etkilemektedir. Nehir kenarında çoğunluğu yazın aktif olan kafe ve restoranlar bulunmaktadır (Sekil 20a, Şekil 20b). 

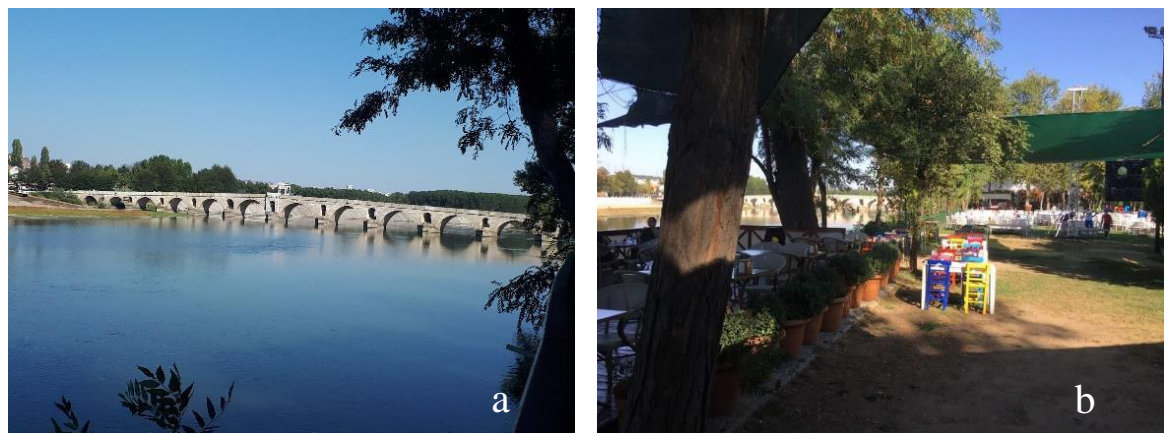

Şekil 20. (a) Meriç Nehri ve Mecidiye Köprüsü, Edirne, (b) Nehir etrafındaki kafeterya ve dinlenme alanları, Edirne

\subsubsection{Eskişehir Porsuk Çayı}

Sakarya Irmağı'nın en uzun kolu olan Porsuk Çayı, Eskişehir'in en önemli doğal güzelliklerinin başında gelmektedir. Eskişehir'in ortasından geçen Porsuk Çayı'nın kuzey tarafında Tepabaşı İlçesi, Güney tarafinda ise Odunparazarı İlçesi bulunmaktadır (URL-8, 2019). Eskişehir Porsuk Çayı rekreasyon amaçlı düzenlemesi ülkemizdeki güzel örneklerden biridir. Nehir ıslah edilmiștir ve bakımları sürekli yapılmaktadır. Yol kotundan belirli aralıklarla nehir kotuna inilebilecek yerler vardır. Doğal bitki örtüsü yanısıra mevsimlik çiçekler ve saksı bitkilendirmeleriyle alanda yeşil doku sağlanmıştır. Nehir üstünde farklı renk ve tasarımlarda köprüler yer almaktadır. Nehir gece ve gündüz olmak üzere günün her saatinde kullanılmakta her yaştan kullanıcıya hitap etmektedir. Nehir boyunca kafe restoranlar, oturma ve dinlenme alanları, eğlence mekanları, yürüyüş yolları ve kayıkla gezinti olanağı bulunmaktadır (Şekil 21a, Şekil 22b).
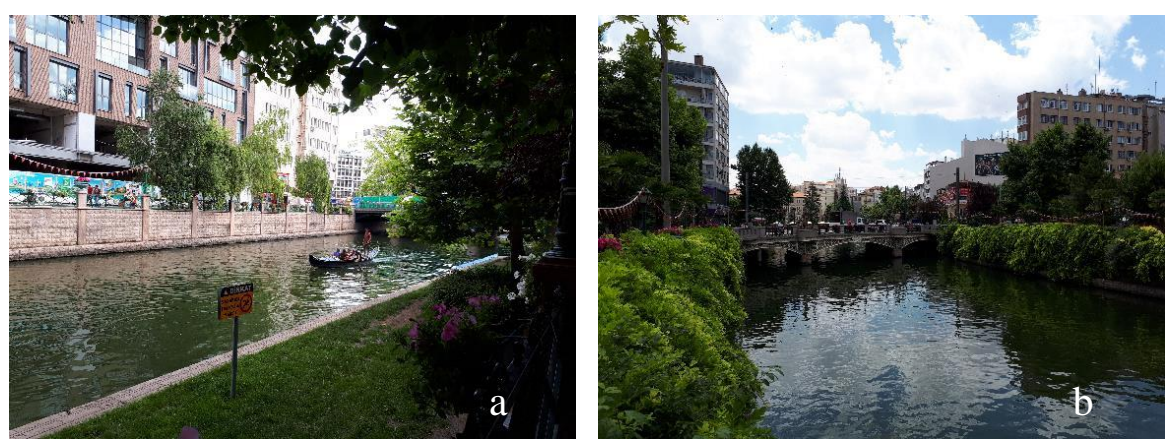

Şekil 21. (a) Porsuk Çayı ve kayıkla gezinti, Eskişehir, (b) Porsuk Çayı üzerindeki köprülerden bir görünüm, Eskişehir
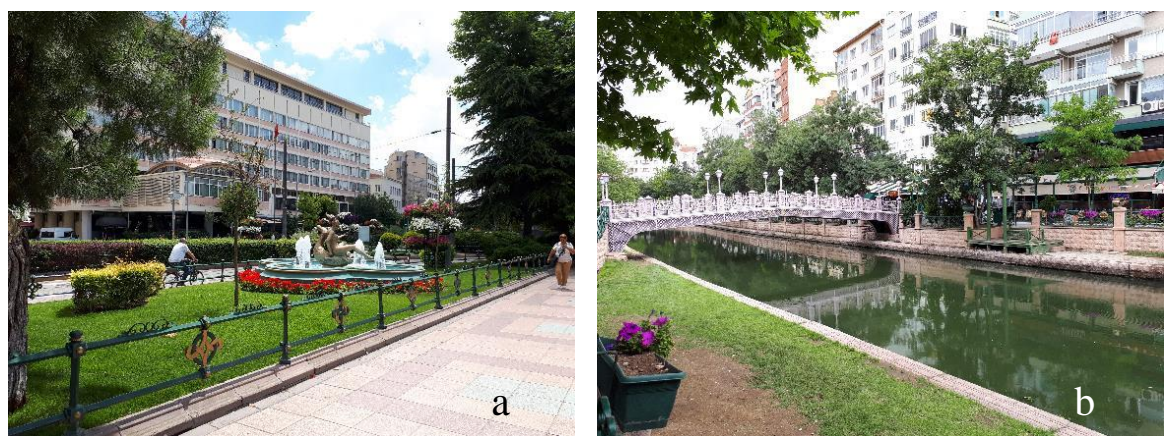

Şekil 22. (a) Nehir çevresinde yer alan yürüyüș, bisiklet yolu ve sanatsal objeler, Eskişehir, (b) Nehir kenarına erişimi sağlayan kot çözümleri, Eskişehir

\section{Tartışma ve Sonuçlar}

İncelenen örneklere bakıldığında su kaynağının insana fiziksel ve ruhsal olumlu etki yaptı̆̆ 1 görülmüștür. Farklı ülkelerde ve farklı kültürlerde bile olsa her insan uygun bulduğu her an suyun çeşitli yararlarından faydalanmak için suyun bulunduğu alana yönelmektedir. Planlama çalışmalarında su kenarlarının bitkisel ve yapısal tasarımlarla zenginleștirilmesi ve mekanın özelliklerini geliştirmekte ve kullanıcılara farklı kullanım olanakları sağlamaktadır. $\mathrm{Bu}$ nedenle 
Hattapoğlu'nun (2004) da vurguladığ kentlerin kuruluşunda nehirler kentlerin iskeletini oluşturmuş; caddelerin, sokakların, parkların ve diğer kentsel mekanların şekillenmesinde etken olmuştur. İncelenen örneklere bakıldığında bu önermenin doğruluğu görülmektedir.

Çalışmada incelediğimiz 5 ülkeye ait 9 nehir örneğinde akarsu içinde ve çevresinde görülen alan kullanımları Tablo 1.de görülmektedir.

Akarsu kenarlarında genellikle balık tutma, bisiklet yolları, eğlence mekanları, hediyelik eşya satış birimleri, oturma dinleme alanları, tekne bot kayık kuru, ticaret alanları ve yeme içme birimlerinin yoğun olduğu görülmektedir. Çalışmanın sonucunda yurt dışındaki örneklere bakıldığında akarsu kaynağının daha verimli kullanıldığı, toplumun her kesimine hitap eden farkl1 kullanımlarla alanın zengin bir kullanım çeşitliliğine sahip olduğu görülmektedir. Yurt içi örneklerden ise en iyi uygulama Eskişehir Porsuk Çayı ve yakın çevresinin kullanımı örnek olarak verilebilir.

İncelenen örneklerde su kaynağının varlığının kentliler için ekonomik ve ticari olanakları beraberinde getirdiği görülmüştür. Bireylerin su kaynaklarını rekreasyonel gereksinimlerle tanıması ve değerlendirmesi, bu ortamlarda yapılacak yeni yatırımların gelişimini artırmıştır.
İncelenen örneklerde akarsu kıyı kullanımlarının toplumun her kesimine ve her yaştan kullanıcıya hitap edecek kullanımları barındırdığ görülmüştür.

Dünyanın birçok ülkesinde kıyı alanlarında koruma, geliştirme, işlev değiştirme gibi çalışmalar yapılmaktadır. Akarsu kıyılarında yapilan projeler yeniden canlandırma, mekânsal kullanım dönüşümü, taşkın kontrolü, akarsu yatağı ve kıyı düzenlemeleri, rekreasyonel alan tasarımı gibi çalışmalardan oluşmaktadır.

Akarsuların barındırdığ çevresindeki yeşil alanlar düşünülerek kullanımları ve korunmaları için bir sistem ve yönetim altına alınmaları gerekmektedir. $\mathrm{Bu}$ şekilde akarsu kıyılarındaki çevre kalitesi artır1labilir.

Akarsu ve çevrelerinin etkin ve verimli kullanımında peyzaj planlama ve tasarım çalışmalarının katkısı büyüktür. Akarsu çevrelerinin kullanım ve korunmaları konusunda yurt dışında görülen olumlu örneklerin ülkemizde de uygulanması doğal kaynakların sürdürülebilirliği açısından yararlı olacaktır. Bu sayede kaliteli çevrelerin artışı sağlanacak ve insanlar için farklı etkinlik alanları kazandırılmış olacaktır.

Tablo 1. İncelenen nehirler ve kullanım türleri

\begin{tabular}{|c|c|c|c|c|c|c|c|}
\hline Nehir & 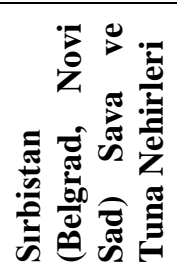 & 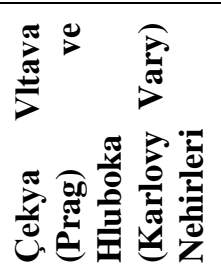 & 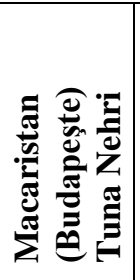 & 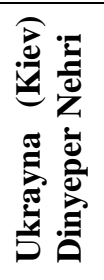 & 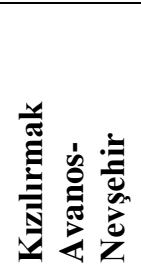 & 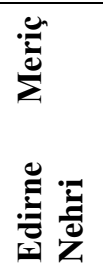 & 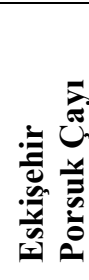 \\
\hline Alışveriş Merkezi & $*$ & * & * & $*$ & & & $*$ \\
\hline Balık Tutma & $*$ & * & $*$ & * & $*$ & $*$ & \\
\hline Bisiklet Yolu & $*$ & * & * & * & $*$ & & $*$ \\
\hline Eğlence Mekanları & * & * & * & * & $*$ & $*$ & $*$ \\
\hline EI Sanat Atölyeleri & * & * & * & * & * & & $*$ \\
\hline $\begin{array}{lll}\text { Hediyelik } & \text { Eşya } & \text { Satış } \\
\text { Birimleri }\end{array}$ & $*$ & * & * & * & $*$ & & $*$ \\
\hline Lunapark & & & & * & & $*$ & \\
\hline Meydan & $*$ & * & * & * & & & \\
\hline Oturma-Dinlenme Alanları & * & * & * & * & $*$ & $*$ & $*$ \\
\hline Otel & & * & * & * & & $*$ & $*$ \\
\hline Seyir Terası & * & * & * & * & * & & $*$ \\
\hline Sokak Sanatı & * & * & * & * & & & $*$ \\
\hline Kamusal Tarihi Yapılar & $*$ & * & * & * & & & \\
\hline Tekne-Bot Kayık Turu & * & * & * & * & $*$ & $*$ & $*$ \\
\hline Ticaret Alanları & * & $*$ & * & * & $*$ & & $*$ \\
\hline Yeme-İçme Alanları & $*$ & * & * & * & * & $*$ & $*$ \\
\hline Yeşil alan & * & $*$ & * & $*$ & $*$ & & $*$ \\
\hline
\end{tabular}




\section{Kaynaklar}

Aksulu, I., 2001. Su, İnsan ve Çevre İlişkileri Üzerine, Mimar.İst Dergisi, 2, 82-84.

Anonim, 1998. Türkçe Sözlük, Türk Dil Kurumu, TDK yayınları, Ankara.

Breen, A., Rigby, D. 1996. The New Waterfront, A Worldwide Urban Success Story. London, 224p.

Cendere, A., 1998. Su Elemanlarının Kentsel Mekanlarda ve Yeşil Alanlarda Kullanımı, Yüksek Lisans Tezi, İTÜ. Fen Bilimleri Enstitüsü, İstanbul, 223s.

Erdal, Z., 2003. Su Elemanlarının Kentsel Mekanlarda Kullanımı 'İstanbul Örneği', Yüksek Lisans Tezi, İTÜ. Fen Bilimleri Enstitüsü, İstanbul, $221 \mathrm{~s}$.

Haris, C.W., Dines, N.T., 1988. Time Saver Standarts for Architecture. Mc Graw-Hill Publishing Company, 640p.

Hattapoğlu, Z., 2004. Su Olgusunun Yerleşmeler Evrimindeki Yeri ve Günümüzde Bir Kentsel Tasarım Elemanı Olarak Yeniden Yorumlanması, Yüksek Lisans Tezi, MSÜ. Fen Bilimleri Enstitüsü, İstanbul, 176s.

Karabey, H., 1978. Kıyı Mekanın Tanımı: Ülkesel Kıyı Mekanının Tanımı İçin Bir Yöntem Önerisi, Doktora tezi, MSÜ. Fen Bilimleri Enstitüsü, İstanbul, 183s.

Kobayashi, H., 1990. Contemporary Landscapes in The World, Topran Printing Co., Tokyo, s.127.

Koskof, S., 1992. Public Places. Bulfinch Press, Boston.

Musayev, E., 2003. Kentsel Kıyı Dolgu Alanları Kullanımı Çerçevesinde Yalova 17 Ağustos Kıyı Parkının Peyzaj Planlama ve Tasarım Açısından İrdelenmesi, Yüksek Lisans Tezi, İ.T.Ü. Fen Bilimleri Enstitüsü, İstanbul, 131s.

Önen, M., 2006. Kentsel Kiyı Mekanı Olarak Akarsuların Rekreasyonel Kullanım Potansiyelinin İrdelenmesi:
Eskişehir Porsuk Çayı ve İstanbul Kurbağalı Dere Örneği, Yüksek Lisans Tezi, İ.T.Ü. Fen Bilimleri Enstitüsü, İstanbul, 203s.

Özmert, N., 1997. Su Ortamında Yaşam ve Yerleşim Üzerine Bir Araştırma, Yüksek Lisans Tezi, YTÜ. Fen Bilimleri Enstitüsü, İstanbul, 291s.

Tekeli, İ., 1976. Kıyı Planlamasının Değişik Boyutları, Mimarlık Dergisi, Mimarlar Odası Yayını, Ankara, 2.

URL-1, http://earth.google.com. 01 Temmuz 2018

URL-2,

http://www.proje4e.com/infoarticles01_11html. 01 Temmuz 2018

URL-3, https://www.interbustur.com/sava-nehri/. 10 Ocak 2019

URL-4, http://www.milliyet.com.tr/tuna-nehri-ninincisi-budapeste-pembenar. 10 Ocak 2019

URL-5, https://www.kievrehberiniz.com/dinyepernehri/. 10 Ocak 2019

URL-6,

http://www.cografya.gen.tr/tr/nevsehir/fiziki.ht ml. 10 Ocak 2019

URL-7, https://www.neredekal.com/meric-nehri/. 10 Ocak 2019

URL-8, https://www.azbibak.com/porsuk-cayieskisehir-hakkinda-bilgi/. 10 Ocak 2019

URL-9, http://www.harikalardiyari.com/amsterdamkanallari/. 10 Ocak 2019

URL-10, https://listelist.com/ganj-nehri-hikayesi/. 10 Ocak 2019

URL-11, https://www.getyourguide.com.tr/london157/?utm_force $=0.10$ Ocak 2019

URL-12, http://www.traveller.com.au/the-mysteriesflowing-in-melbournes-yarra. 10 Ocak 2019

URL-13, https://www.livemint.com/Companies/IEVh420 zqXh2GzPdLInYOJ/. 10 Ocak 2019 